\title{
A comparative study of lipid profile in first attack versus relapse cases of idiopathic nephrotic syndrome in children
}

\author{
Upadhyay M.R. ${ }^{1}$, Beriha S.S. ${ }^{2}$, Pradhan S.K. ${ }^{3}$ \\ ${ }^{1}$ Dr. Manas Ranjan Upadhyay, ${ }^{2}$ Dr. Siba Shankar Beriha, ${ }^{3}$ Dr. Subal Kumar Pradhan, all authors are affiliated with \\ Department of Pediatrics, Sardar Vallav Bhai Patel Post Graduate Institute of Pediatrics (SVPPGIP) \& S.C.B Medical \\ College, Cuttack, Orissa, India.
}

Corresponding Author: Dr. Siba Shankar Beriha, Asst. Professor, Department of Pediatrics, SVPPGIP, SCB Medical College, Cuttack, Odisha, India. E-mail: dssb1975@gmail.com

\begin{abstract}
Objectives: Nephrotic dyslipoprotenemia usually revert to normal with remission but hyperlipidemia is a well known risk factor of atherosclerosis and glomerular injury in children. There are few studies comparing the spectrum of dyslipidemia in initial attack and subsequent relapses of nephritic syndrome. The aim of the study was to compare the lipid profile in first attack and relapse cases of Idiopathic Nephrotic Syndrome in children. Methodology: The prospective study was conducted between May 2015-June 2017 at S.V.P.P.G.I and S.C.B Medical College, Cuttack. Total of 55 cases of Idiopathic Nephrotic Syndrome of aged 1 to 14 years were included in the study. Out of 55 cases 30 cases were in first attack and 25 cases were in the relapses group. The demographic data, lipid profile, magnitude of hyperlipidemia and serum albumin were analyzed in the study. Results: The total serum cholesterol level $(470+116)$ $\mathrm{mg} / \mathrm{dl}$ was higher in relapse cases as compared to first attack group. Similarly serum TG (305+115) mg/dl, LDL $(354+126) \mathrm{mg} / \mathrm{dl}$, VLDL $(59+24) \mathrm{mg} / \mathrm{dl}$ level was higher in relapse cases. However serum HDL (41+8) $\mathrm{mg} / \mathrm{dl} \mathrm{was}$ found to be lower in relapse group as compared to first attack. The serum Albumin level $(<2.5 \mathrm{gm} / \mathrm{dl})$ was low in all cases but in $12 \%$ cases $(\mathrm{n}=4)$ of relapse group was very low $(<1.0 \mathrm{gm} / \mathrm{dl})$. Conclusion: This establishes a higher serum cholesterol, TG, LDL, VLDL and marginally lower HDL level in relapse group as compared to first attack which may be explained by lower serum Albumin level causing higher lipid profile. This emphasis the need of close monitoring of lipid profile and in all further episode of relapse group for dietary modification and early intervention.
\end{abstract}

Key words: Idiopathic Nephrotic Syndrome, Dyslipidemia, Relapse, Lipid profile

\section{Introduction}

Nephrotic syndrome is an important chronic disease in children characterized by heavy proteinuria, hypoalbunimea, hyperlipidemia and edema. One of the most pronounced secondary changes in children with nephritic syndrome is lipoprotein metabolism. The changes are of a quantative as well as a qualitative nature [1]. All apolipoprotein B (apo B) containing lipoproteins, such as very low density lipoproteins (VLDL), intermediate- density lipoproteins (IDL), low density lipoproteins (LDL) and lipoprotein (a) [Lpa] are elevated in nephrotic syndrome.

High density lipoproteins (HDL) are reported to be unchanged or reduced [2]. There is a direct relationship between the plasma HDL concentration and its

Manuscript received: $18^{\text {th }}$ November 2018

Reviewed: $28^{\text {th }}$ November 2018

Author Corrected: $5^{\text {th }}$ December 2018

Accepted for Publication: $9^{\text {th }}$ December 2018 biological half-life; Hence, increased hepatic synthesis of HDL begins to expand the pool size but because of no compensatory increase in the number of catabolic receptors, the HDL lost in the urine probably increases as the plasma concentration rises. Thus, the HDL levels in patients remained at the same levels as controls. HDL may be lost in the urine and dependent or whether or not increased synthesis can match the rate of loss, the HDL may be low or normal [1]. The pathophysiology of nephrotic dyslipoproteinemia is multifactorial, including both an increased hepatic synthesis and a diminished plasma catabolism of lipoproteins.

The severity of hyperlipidemia tends to correlate with severity of hypoalbuminemia [3,4]. These changes usually revert to normal with remission of the nephritic syndrome. But recent studies show that nephrotic syndrome may have prolonged periods of 
hyperlipidemia even after clinical remission [5], persistence and severity of lipid changes correlating well with duration of disease and frequency of relapses. There are two potential risks of elevated plasma lipids: atherosclerosis and accelerated progression of glomerular injury by favouring mesangial sclerosis leading to progression of renal disease [6].

There is increasing consensus that lipid levels in children to a large extent determine the rate of coronary artery disease (CAD) in adult population. There are few studies comparing the spectrum of dyslipidemia in initial attack and subsequent relapses of nephrotic syndrome. The aim of the study was to compare the lipid profile in first attack and relapse cases of Idiopathic Nephrotic Syndrome in children.

\section{Materials and Method}

Place and type of study:- This is a prospective study conducted in the department of pediatrics, between May 2015-June 2017 at S.V.P.P.G.I.P and S.C.B Medical College, Cuttack, ODISHA. Sampling Method:-All indoor patients diagnosed to be idiopathic nephrotic syndrome between 1 to 14 years are taken as sample for the study.

Inclusion criteria:- All idiopathic nephrotic syndrome between 1 to 14 years are included in the study.

Exclusion criteria: All secondary nephrotic syndrome, infantile nephrotic syndrome and nephrotic syndrome in children above 14 years, and children presenting with clinical feature suggestive of non minimal change nephrotic syndrome and familial hypercholesteremia are excluded from the study.

Statistical Method: Detailed history was taken and thorough clinical examination was done. The demographic data, lipid profile, magnitude of hyperlipidemia and serum albumin were analyzed in the study. In fasting state blood collection was done in early
Original Research Article

morning and the samples were analysed for serum total proteins, serum albumin, serum globulin, blood urea, serum creatinine, and lipid profile (total cholesterol, triglycerides, LDL, VLDL, HDL). Lipid profile lebel was measured on admission to the hospital and again in remission at 1st attack and as well as in relapse cases.

We estimated Serum protein by modified Lowry's method, serum albumin by Biuret method, urinary proteins were estimated by Esbachs albuminometer. Blood urea was estimated by Diacetyl monoxime method, serum creatinine was estimated by Jaffes method [7].

Serum total cholesterol was measured by cholesterol oxidase phenol amino antipyrine (CHOD-PAP) method, serum triglycerides were estimated by acetyl acetone method, LDL cholesterol was estimated by ammonium ferrothiocyanate method, VLDL cholesterol was measured by enzymatic method, Serum HDL Cholesterol was measured by phosphotungstate method $[8,9,10]$.

Statistical analysis was done by descriptive statistics, as per standard protocol with mean, median and standard deviation. SPSS-16 was used for data analysis.

Sample collection: Total of 55 cases of Idiopathic Nephrotic Syndrome of aged 1 to 14 years were included in the study. The diagnosis of nephrotic syndrome was based on the guidelines of Indian Pediatric Nephrology Group, [11], on the presence of 1) Edema 2) Nephrotic range proteinuria (urine protein $3+/ 4+$ on dipstick or boiling or spot protein/ creatine ratio >2) 3) Hyperlipidemia (serum cholesterol $>200 \mathrm{mg} / \mathrm{dl}$ ) and 4) Hypoalbunemia (serum albumin $<2.5 \mathrm{~g} / \mathrm{dl}$ ). Remission was defined as presence of urine albumin $3+$ or $4+$ (or proteinuria $>40 \mathrm{mg} / \mathrm{m} 2 / \mathrm{h}$ ) for 3 consecutive early morning specimens, having been in remission previously. Out of 55 cases, 30 cases were in first attack and 25 cases were in the relapses group.

\section{Results}

Out of 30 cases of first attack group 16 cases were male and 14 cases female child. In the relapse group out of 25 cases 15 cases were male and 10 cases were female child. Majority of children in both groups were between 1-5 years. The total serum cholesterol level $(470+116) \mathrm{mg} / \mathrm{dl}$ was higher in relapse cases as compared to first attack group.

Similarly serum TG $(305+115) \mathrm{mg} / \mathrm{dl}$, LDL $(354+126) \mathrm{mg} / \mathrm{dl}$, VLDL $(59+24) \mathrm{mg} / \mathrm{dl}$ level was higher in relapse cases. However serum HDL $(41+8) \mathrm{mg} / \mathrm{dl}$ was found to be lower in relapse group as compared to first attack as shown in the table1.

The serum Albumin level $(<2.5 \mathrm{gm} / \mathrm{dl})$ was low in all cases but in $16 \%$ cases $(\mathrm{n}=4)$ of relapse group was very low $(<1.0$ $\mathrm{gm} / \mathrm{dl})$ as shown in the table 2 . 
Table-I: Comparison of lipid profile in First attack and Relapse in children with nephritic syndrome.

\begin{tabular}{|c|c|c|}
\hline Serum lipid profile (mg \%) & First attack & Relapse \\
\cline { 2 - 3 } & Mean + SD & Mean + SD \\
\hline Total cholesterol & $373.3+80.7$ & $470.3+116.2$ \\
\hline Triglycerides (TG) & $237.2+70.5$ & $305.8+115.8$ \\
\hline HDL-cholesterol & $46.4+9.5$ & $41.8+8.3$ \\
\hline LDL-cholesterol & $272.8+77.3$ & $354.5+126.6$ \\
\hline VLDL-cholesterol & $49.5+17$ & $59.3+24.3$ \\
\hline Total cholesterol/HDL ratio & $8.3+2.3$ & $11.8+4.8$ \\
\hline LDL/HDL ratio & $6.1+2.3$ & $7.4+3.7$ \\
\hline
\end{tabular}

Table-II: Correlation between serum Albumin and total cholesterol in First attack and Relapse in nephrotic syndrome.

\begin{tabular}{|c|c|c|c|c|c|c|}
\hline Serum Albumin & Total Cases & \multicolumn{4}{|c|}{ Serum Cholesterol (mg /dl) } & \multirow[t]{2}{*}{ P value } \\
\hline First Attack & $\mathrm{N}=30$ & $201-300$ & $301-400$ & $401-500$ & $>500$ & \\
\hline $0.5-0.9$ & 0 & 0 & 0 & 0 & 0 & \\
\hline $1.0-2.0$ & $22(73.3 \%)$ & 5 & 9 & 5 & 3 & 0.001 \\
\hline $2.1-2.5$ & $8(26.7 \%)$ & 3 & 2 & 3 & 0 & \\
\hline$>2.5$ & 0 & 0 & 0 & 0 & 0 & \\
\hline Relapse & $\mathrm{N}=25$ & & & & & \\
\hline $0.5-0.9$ & $4(16 \%)$ & 0 & & 1 & 3 & \\
\hline $1.0-2.0$ & $19(76 \%)$ & 0 & 2 & 9 & 8 & 0.001 \\
\hline $2.1-2.5$ & $2(8 \%)$ & 0 & 2 & 0 & 0 & \\
\hline$>2.5$ & 0 & 0 & 0 & 0 & 0 & \\
\hline
\end{tabular}

\section{Discussion}

Out of 55 children with nephrotic syndrome most were between 1-5 years age-74\% in First attack, 64\% in Relapse group. In the first attack group 53\% were male and $47 \%$ were female, as compared to $60 \%$ males and
$47 \%$ females in the Relapse group. So a male preponderance was noticed in First Attack and Relapse group. [12] Heyman et al (1972), [13] Srivastav et al (1975) has reported as 2:1 male to female ratio. 
Comparison of complete lipid profile in the first attack and relapse cases showed that total serum cholesterol level, mean $(470+116) \mathrm{mg} / \mathrm{dl}$ was higher in relapse cases as compared to first attack group [14]. Mahmud S, Jahan (2011) had similar findings in their study.

Arije et al [15] also observed persistent rise in serum cholesterol in frequent relapse cases. Similarly serum TG (305+115) mg/dl, LDL (354+126) mg/dl, VLDL $(59+24) \mathrm{mg} / \mathrm{dl}$ level was also higher in relapse cases [16]. Dnyanesh DK, Suma Dnyanesh (2014) had similar observation in their study.

However serum HDL $(41+8) \mathrm{mg} / \mathrm{dl}$ was found to be lower in relapse group as compared to first attack [1]. The present study shows that lipid profile in first episode of nephrotic syndrome reaches normal value during remission, whereas in relapse cases, there is persistent elevation in the lipid profiles even during the remission [17].

Merouani et al observed hyperlipidemia during the active phase of the disease and disappeared with resolution of the proteinuria and was persistently abnormal in frequently relapsing children. [14].

Mahmud S et al observed that children with frequently relapsing nephrotic syndrome have prolonged periods of hypercholesterolemia and concluded that serum cholesterol may be regarded as predictor of relapse in childhood idiopathic nephrotic syndrome.

The higher level of lipid profile in relapse compared to first attack is explained by: 1) Marked and on going damage to glomerulus by previous hyperlipidemia as suggested by [18].

2) Lipid level may remain high even during remission as suggested by various studies [17]. Any relapse during this period is therefore likely to increase the lipid level further as suggested there is increased suppressor $\mathrm{T}$ cell activity during Relapse as suggested by [19] Eljouki AY also low levels of IgG as suggested by [20] Meadow et al therefore there is increased chance of infection and further likely diminution of serum protein level resulting hyperlipidemia.

Comparing the serum albumin level in 1st attack versus relapse group, it was more low in relapse than in first attack group, [21] White at al and [22] Srivastava et al report a similar incidence of hypoalbuminemia. This may be explained by heavy proteinuria in first attack and probably inadequate nutritional and protein supplementation after remission or associated infection
Original Research Article

which have triggered relapse. [23] As per Kaysen (1993) only the liver protein undergoes an increased synthesis but certain other proteins are not immediately made up and so cause low serum total protein concentration.

There was a significant correlation between albumin and cholesterol in our study, which is similar to [24] Thomas et al who found the correlation as statistically significant which is due to hepatic lipoprotein synthesis is stimulated in response to hypoalbuminemia, low oncotic pressure and urinary albumin loss but [25] Krishnaswamy et al found the correlation as not statistically significant.

There is a need of monitoring lipid profile in nephrotic syndrome, because altered lipid profile lead to long term cardiovascular morbidity and progression of renal disease favouring mesangial sclerosis. It is prudent to evaluate the lipid and lipoprotein levels early and treat hyperlipidemia in these patients for preventive reasons.

\section{Conclusion}

This establishes a higher serum cholesterol, TG, LDL, VLDL and marginally lower HDL level in relapse group as compared to first attack which may be explained by lower serum Albumin level causing higher lipid profile. Thus, a combination of increased hepatic synthesis and decreased removal of lipoproteins from plasma is thought to be present in nephrotic syndrome. This emphasizes the need of close monitoring of lipid profile and in all further episode of relapse group for dietary modification and early medical intervention to prevent long term cardiovascular morbidity and progression of renal disease .

Contributions: SSB-did the design, analysis and manuscript writing; MRU- did the data collection and analysis; SKP-was involved with analysis and manuscript writing.

What this study adds to existing knowledge:-long term monitoring of serum lipid profile is essential because if not monitored meticulously lead to further kidney damage and longterm cardiovascular morbidity.

Funding: Nil, Conflict of interest: None initiated, Perission from IRB: Yes

\section{References}

1. Kronenberg F. Dyslipidemia and nephrotic syndrome: recent advances. J Ren Nutr. 2005 Apr;15 (2) : 195-203. 


\section{Original Research Article}

2. Marsh JB. Lipoprotein metabolism in the nephrotic syndrome. Front Biosci. 2002 Aug 1;7:e326-38.

3. Appel GB, Blum CB, Chien S, et al. The hyperlipidemia of the nephrotic syndrome. Relation to plasma albumin concentration, oncotic pressure, and viscosity. N Engl J Med. 1985 Jun 13;312(24):1544-8.DOI:10. 1056/ NEJM198506133122404

4. Gheradi E, Rota E, Calandra S et al.Relationship among the concentration of serum lipoproteins and changes in their chemical composition in patients with untreated nephrotic syndrome. Eur J Clin Invest, 1997; 7:567-570.

5. Gaston Zilleruelo, Sung L. Hsia, Michael Freundlich, Helen M. Gorman, Jose Strauss. Persistence of serum lipid abnormalities in children with idiopathic nephrotic syndrome, January 1984,volume 104,issue 1, pages 6164, DOI: https: //doi.org/10.1016/ S0022-3476 (84) 80590-9

6. Kamanna VS, Bassa BV, Ganji SH. Low density lipoproteins transactivate EGF receptor: role in mesangial cell proliferation. Life Sci. 2008 Oct 24;83 (17-18): 595-601. doi: 10.1016/j.1fs.2008.08.010. Epub 2008 Sep 6

7. Varley H, Gowenlock AH, Bell M. Practical Clinical Biochemistry. Fifth Edition; Jaypee Brothers. India. 1991:1:126-8.

8. Searcy RL, Bergquist LM. A new color reaction for the quantitation of serum cholesterol. Clin Chim Acta. 1960 Mar;5:192-9.

9. Fletcher MJ. A colorimetric method for estimating serum triglycerides. Clin Chim Acta. 1968 Nov; 22 (3): 393-7.

10. Stewart JC. Colorimetric determination of phospholipids with ammonium ferrothiocyanate. Anal Biochem. 1980 May 1;104(1):10-4.

11. Consensus Statement on management of steroid sensitive nephritic syndrome. Indian Pediatric Nephrology Group, Indian Academy of Pediatrics. Indian Pediatric 2001; 38:975-986

12. Walter Heymann, Sudesh P. Makker, The Idiopathic Nephrotic Syndrome of Childhood, A Clinical Re evaluation of 148 Cases Am J Dis Child. 1974;127 (6):
830-837. doi: 10.1001/ archpedi. 1974.0211025005 6008

13. Srivastava RN, Bagga A. Nephrotic syndrome in : Pediatric Nephrology. $4^{\text {th }}$ edition $.2005: 161-200$

14. Mahmud S, Jahan S, Hossain MM. Hyperlipidemia in childhood idiopathic nephrotic syndrome during initial remission and relapse. Mymensingh Med J. 2011 Jul; 20 (3):402-6.

15.Arije A, Erasmus RT, Anjorin SA. Plasma lipids and lipoproteins cholesterol distributions in nephrotic syndrome patients during short term steroid treatment. Cent Afr J Med. 1993;39:211-5.

16. Dnyanesh DK, Suma Dnyanesh, Varadaraj Shenoy. A Study of Serum Lipids in Nephrotic Syndrome in Children. IOSR Journal of Dental and Medical Sciences (IOSR-JDMS) e-ISSN: 2279-0853, p-ISSN: 2279-0861. Volume 13, Issue 3 Ver. I. (Mar. 2014), PP01-06,

17. Merouani A, Levy E, Mongeau JG, Robitaille P, Lambert M, Delvin EE. Hyperlipidemic profiles during remission in childhood idiopathic nephrotic syndrome. Clinic Biochem. 2003;36:571-4.

18. Moorhead JF, Chan MK, El-Nahas M, et al. Lipid nephrotoxicity in chronic progressive glomerular and tubulo-interstitial disease. Lancet. 1982 Dec 11;2 (8311): 1309-11.

19. Elzouki AY. Immunological aspect of primary nephrotic syndrome in childhood. Saudi J Kidney Dis and Transplant 1994;5:483-8

20. Meadow SR, Sarsfield JK, Scott DG, et al, Steroidresponsive nephrotic syndrome and allergy: immunological studies. Archives of Disease in Childhood 1981;56:517-524.

21.R.H.R White, E.F Glasgow, R.JMills, clinicopathological study of nephrotic syndrome in childhood, The Lancet, Volume 295, Issue 7661, 27 June 1970, Pages 1353-1359.

22. Srivastava RN, Mayekar G, Anand R, et al. Nephrotic syndrome in indian children. Arch Dis Child. 1975 Aug;50(8):626-30.

23. Kaysen GA, Davies RW.Reduction in proteinuria attenuates hyperlipidemia in the nephrotic syndrome. $\mathrm{J}$ Am Soc Nephrol.1990;1(suppl 2):S75-79 
24. Thomas EM, Rosenblum AH, Lander HB, et al. Relationships between blood lipid and blood protein levels in the nephrotic syndrome. AMA Am J Dis Child. 1951 Feb;81(2):207-14.
25. Krishnaswamy $\mathrm{D}$, Indumati $\mathrm{V}$, Sathishkumar D, Vijay V, Shekanawar M. Serum proteins, initial and follow up lipid profile in children with nephrotic syndrome.Int J Applied Bio Pharma Tech. 2011;2:59-64

\section{How to cite this article?}

Upadhyay M.R, Beriha S.S., Pradhan S.K. A comparative study of lipid profile in first attack versus relapse cases of idiopathic nephrotic syndrome in children. Int J Pediatr Res. 2018;5(12):636-641.doi:10.17511/ijpr.2018.i12.05. 